
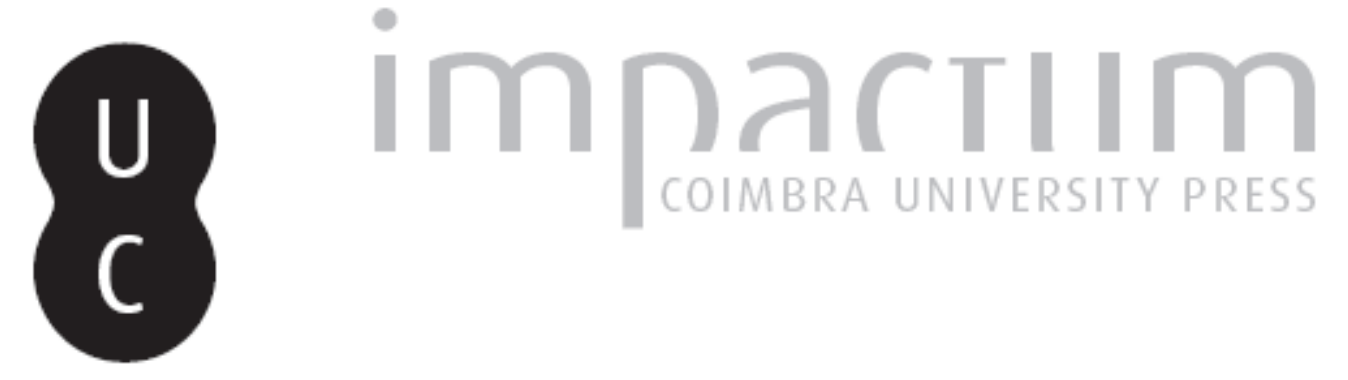

\title{
Análise da política de comunicação da União Europeia no quadro da recusa na adopção do tratado que estabelece uma constituição para a Europa
}

Autor(es): $\quad$ Figueiredo, Alexandre

$\begin{array}{ll}\text { Publicado por: } & \text { Centro de Informação Europe Direct de Aveiro; Centro de Estudos } \\ \text { Interdisciplinares do Século XX }\end{array}$

URL

persistente:

URI:http://hdl.handle.net/10316.2/33979

DOI:

DOI:http://dx.doi.org/10.14195/1647-6336_11_8

Accessed : $\quad$ 26-Apr-2023 16:37:29

A navegação consulta e descarregamento dos títulos inseridos nas Bibliotecas Digitais UC Digitalis, UC Pombalina e UC Impactum, pressupõem a aceitação plena e sem reservas dos Termos e Condições de Uso destas Bibliotecas Digitais, disponíveis em https://digitalis.uc.pt/pt-pt/termos.

Conforme exposto nos referidos Termos e Condições de Uso, o descarregamento de títulos de acesso restrito requer uma licença válida de autorização devendo o utilizador aceder ao(s) documento(s) a partir de um endereço de IP da instituição detentora da supramencionada licença.

Ao utilizador é apenas permitido o descarregamento para uso pessoal, pelo que o emprego do(s) título(s) descarregado(s) para outro fim, designadamente comercial, carece de autorização do respetivo autor ou editor da obra.

Na medida em que todas as obras da UC Digitalis se encontram protegidas pelo Código do Direito de Autor e Direitos Conexos e demais legislação aplicável, toda a cópia, parcial ou total, deste documento, nos casos em que é legalmente admitida, deverá conter ou fazer-se acompanhar por este aviso. 
DEBATER

A EUROPA

jul-dez 2014

QUE EUROPA(S)?

CONTEXTOS E DESAFIOS 


\title{
Análise da Política de Comunicação da União Europeia no quadro da recusa na adopção do Tratado que Estabelece uma Constituição para a Europa
}

\author{
Alexandre Figueiredo \\ Doutor em Ciências da Comunicação \\ Membro Doutorado do Centro de Investigação Media e Jornalismo \\ Membro Efectivo e do Conselho Científico do Centro de Investigação Professor \\ Doutor Joaquim Veríssimo Serrão \\ E-mail: ampfigueiredo@gmail.com
}

\section{Resumo}

Desde que, em 2005, franceses e neerlandeses reprovaram a adopção do Tratado Constitucional os sinais de crise no projecto europeu, tornaram-se por demais evidentes. Entre as causas referidas estão o défice democrático e o défice de comunicação. Impunha-se, por isso, uma profunda alteração da política de comunicação das instituições comunitárias. Entre os canais escolhidos para o efeito destaca-se a aposta na Internet. Justifica-se, assim, uma análise de enquadramentos aos principais documentos, produzidos pela UE no sentido de aferir de que modo estão as TIC a ser usadas na mitigação do deficit de comunicação e consequente reforço da mensagem europeia.

Palavras-chave: défice democrático; défice de comunicação; União Europeia; política de comunicação Europeia; análise de enquadramentos

\begin{abstract}
:
Since, in 2005, French and Dutch disapproved the adoption of the Constitutional Treaty that, signs suggesting a crisis in the European project, have become all too apparent. Among the causes mentioned are both democratic deficit and communication deficit. It
\end{abstract}


seemed, therefore, necessary a profound change of the European institutions communication policy. Among the selected channels to accomplish this objective is the Internet. Hence it is justified a policy frame analysis to the key documents produced by the EU, in order to assess how ICTs are being used to mitigate communication deficit and consequently enhance the European message.

Keywords: democratic deficit, communication deficit, European Union, communication policy, policy frame analysis

\section{Introdução}

Desde o início do século XXI sucessivos acontecimentos vêm testando a coesão e determinação dos Europeus em levar por diante o projecto de integração que uniu as lideranças políticas e os cidadãos da Europa na segunda metade do século XX.

Com efeito, se no decurso das primeiras décadas das Comunidades Europeias, as divisões se centravam principalmente ao nível da arquitectura institucional, os acontecimentos recentes têm exposto outras fragilidades e insuficiências que eram, até há bem pouco tempo, largamente desconhecidas do grande público.

A estas junta-se ainda uma aparente crescente recusa, por parte dos próprios povos da União Europeia, em validarem o desejável e necessário aprofundamento da integração. Exemplos disto mesmo são os problemas sentidos na ratificação dos Tratados de Maastricht, Nice e Lisboa mas, sobretudo, a recusa na adopção do Tratado que Estabelece uma Constituição para a Europa.

De facto, para a generalidade dos indivíduos, a União Europeia permanece uma complexa teia burocrática cuja compreensão lhes é, em grande medida, inacessível. Paralelamente, a capacidade de intervenção dos cidadãos na condução da política europeia esbarra num autismo institucional que inibe a participação e promove o afastamento. No entanto, só após a reprovação, por parte de franceses e neerlandeses, em sede de referendo, do Tratado Constitucional, a União Europeia parece ter-se dado conta da verdadeira dimensão do problema, decretando, em consequência, um período de reflexão.

Entre as causas mais comuns para o afastamento dos cidadãos do desígnio da Europa unida parece estar uma certa ideia de défice democrático, cujos efeitos a política de comunicação das instituições europeias se tem revelado incapaz de inverter, fenómeno genericamente definido por défice de comunicação. Vejamos, por 
conseguinte, de modo mais aproximado um e outro, com vista a, em momento posterior, empreendermos uma análise de enquadramentos à política de comunicação da própria União Europeia.

\section{Défice Democrático}

Entre as fragilidades mais comuns apontadas ao projecto de integração europeia destacam-se, com excepção dos eleitos para o Parlamento Europeu, a falta de legitimidade directa dos responsáveis pelas instituições e, principalmente, excluindo-se uma minoria de Estados-Membros, o facto de os sucessivos Tratados das Comunidades e da União Europeia, não terem sido alvo de auscultação popular, bem como do necessário debate interno ${ }^{1}$. Esta é a perspectiva de Bowman (2006: 191-192). O autor lembra que, para fazer parte da União Europeia, um Estado tem de cumprir duas condições básicas: respeitar os direitos humanos e as regras democráticas. Porém, ao nível supra-estadual, a própria União não cumpre qualquer destes quesitos. Primeiro porque a própria UE ainda não formulou uma política comum de direitos humanos ${ }^{2}$. Depois porque, embora as instituições comunitárias influenciem decisivamente a vida quotidiana dos cidadãos, a verdade é que existem poucas evidências sugerindo que os indivíduos consigam influenciar o processo decisório da $\mathrm{UE}^{3}$. Como sugere Mouchon (2005: 2) o desconhecimento quase geral dos cidadãos relativamente aos modos de funcionamento da UE em muito contribui para tal situação.

Existem todavia outros aspectos a considerar. Por um lado a UE anuncia pretender um maior envolvimento dos cidadãos no processo de construção europeu. No entanto, a vontade popular, quando convocada, nem sempre é respeitada. O "Não" irlandês ao Tratado de Nice ${ }^{4}$, repetido, posteriormente num segundo momento em $2008^{5}$

\footnotetext{
${ }^{1} \mathrm{O}$ caso português é, aliás paradigmático, posto que, a população nunca foi chamada a pronunciar-se sobre qualquer destas questões: os portugueses não votaram a adesão às Comunidades, não ratificaram qualquer dos Tratados, não foram auscultados na decisão de integração na moeda única, e o escasso debate interno ocorrido, foi-o ao nível das elites.

${ }^{2} \mathrm{O}$ Tratado de Nice foi incapaz de cumprir esta meta, igualmente inviabilizada pela reprovação na França e Países Baixos do Projecto que estabelecia um texto constitucional para a Europa. Recorde-se que a Constituição Europeia previa, na sua Parte II (arts. II-61. ${ }^{\circ}$ a II-114. ${ }^{\circ}$ ), a reprodução, com algumas alterações pontuais, da "Carta dos Direitos Fundamentais da União Europeia" (Gorjão-Henriques, 2008ª 98 e 103-104). Com o Tratado de Lisboa, a Carta dos Direitos Fundamentais foi relegada para um mero anexo, num exercício que Gorjão-Henriques (2008ª : 110, seguindo Pennera) apelidou de desaparecimento fictício.

${ }^{3}$ A este respeito, vd. Crombez (2003: 102.

4 Vd. [em linha]: http://www.tsf.pt/PaginaInicial/Interior.aspx?content_id=785809 e; [em linha]: http://www.publico.pt/Mundo/tratado-de-nice-em-risco-com-nao-irlandes-actualizacao-26641.

5 Vd. [em linha]: http://www.publico.pt/Mundo/ue-irlanda-rejeitou-tratado-de-lisboa-1332224 e; [em linha]: http://www.dw.de/dw/article/0,3411142,00.html.
} 
relativamente ao Tratado de Lisboa ${ }^{6}$, representa por si só um elemento paradigmático deste paradoxo.

Acresce ao referido no parágrafo anterior, a percepção generalizada que a acção e as decisões da União Europeia são, na sua globalidade, fortemente condicionadas por um directório de países, cuja face mais visível, nos últimos anos, consistiu, ainda que nem sequer exclusivamente, na aliança franco-germânica protagonizada pelos respectivos líderes ${ }^{7}$.

Por fim, Crombez (2003: 102) reporta ainda uma fonte adicional susceptível de contribuir para o sentimento de défice democrático: a ausência de mecanismos de responsabilidade democrática no interior das instituições da União Europeia resulta num fenómeno que é dificilmente compreensível pelo cidadão eleitor. Esta mesma questão foi ainda recentemente suscitada pelo eurodeputado britânico Nigel Farage, o qual criticou ferozmente os decisores europeus ${ }^{8}$.

Se limitássemos a nossa reflexão a estes episódios e àquelas que têm sido as práticas mais recentes das instituições comunitárias, seríamos tentados a concluir pela existência de um profundo défice democrático no seio da União Europeia. Porém, este é apenas um lado da equação.

Diferentemente, Crombez (2003: 103-104) propõe um itinerário alternativo. No trabalho que empreendeu o autor (2003: 106) apresenta um modelo de análise que contrapõe os diversos modelos de arranjo institucional (via de regra, federações) com o modelo da União Europeia. Assim, refere um Parlamento bicamaral (composto por uma câmara alta que representa os estados e uma câmara baixa que representa os povos) e um executivo (que é eleito por uma das, ou por ambas as, câmaras). Deste modo, conclui que "[...] este não é um arranjo institucional invulgar e de modo algum um que

\footnotetext{
${ }^{6}$ Recorde-se que o Tratado de Lisboa teve de ser referendado duas vezes na Irlanda, apenas sendo ratificado na sequência de um segundo referendo. Vd. [em linha]: http://www.publico.pt/Mundo/governoirlandes-assume-vitoria-do-sim-ao-tratado-de-lisboa-1403542; [em linha]:

http://pt.euronews.com/2009/10/03/irlanda-diz-sim-ao-tratado-de-lisboa-em-referendo/ e; [em linha]: http://www.jn.pt/PaginaInicial/Mundo/Interior.aspx?content_id=1380778.

${ }^{7} \mathrm{Na}$ verdade, foram relatadas na comunicação social, ao longo deste período e em diferentes ocasiões, mini-cimeiras entre o ex-governante francês Nicholas Sarkozy e a chanceler alemã Angela Merkel, as quais visavam a definição de uma estratégia comum a apresentar (o termo impor também foi empregue amiúde) nas diferentes cimeiras europeias. Vejam-se alguns dos exemplos referentes ao ano de 2011: [em linha]: http://www.dn.pt/inicio/economia/interior.aspx?content_id=1952858; [em linha]:

http://expresso.sapo.pt/cimeira-merkel-sarkozy-adia-decisoes=f679297; [em linha]:

http://www.publico.pt/Mundo/merkel-e-sarkozy-discutem-hoje-propostas-para-a-cimeira-europeia-

1523779; [em linha]: http://visao.sapo.pt/merkel-e-sarkozy-chegaram-a-acordo-sobre-novo-resgategrego=f613862; [em linha]: http://visao.sapo.pt/uecimeira--merkel-sarkozy-vao-negociar-reestruturacaogrega-com-banqueiros=f629964; [em linha]:

http://www.jn.pt/PaginaInicial/Nacional/Interior.aspx?content_id=1775905.

${ }^{8}$ Vd. [em linha]: http://www.youtube.com/watch?feature=player_embedded\&v=dLf0wfMFOaw.
} 
seja inerentemente anti-democrático" (Crombez, 2003: 111, tradução nossa). Na verdade, "[a] UE dispõe de uma legislatura bicamaral, e um executivo designado por ambas as câmaras da legislatura. [...] Se existe um défice democrático na UE que é significativamente maior que noutros sistemas políticos, se a política da UE tende a estar muito afastada do votante médio da UE, não é por conseguinte um resultado do arranjo institucional da UE, nem é uma consequência do procedimento legislativo que as instituições usam" (Crombez, 2003: 111, tradução nossa).

No mesmo sentido, Moravcsik (2002) pensa que, ao contrário do que é habitual referir-se, a União Europeia representa, com efeito, um modelo que não carece das insuficiências de legitimidade que lhe são habitualmente apontadas. "As suas instituições (escreve o autor, 2002: 603, tradução nossa) estão constrangidas por apertados poderes e contra-poderes constitucionais: mandatos estreitos, limites fiscais, requerimentos de votação concorrentes e super-maioritários e separação de poderes".

Em suma, os dados reunidos parecem sugerir duas realidades distintas. Num sentido, a arquitectura institucional da UE não apresenta, em termos formais, desvios fundamentais face a outras experiências análogas. Em sentido inverso, pelo contrário, diversas pistas apontam para uma realidade de facto que se distancia do desenho institucional. Dito de outro modo: se no plano institucional o défice democrático pode ser um mito, bem diferente parece ser a praxis quotidiana.

\section{Défice de Comunicação}

Seja porque os Estados nacionais tendem a "atirar" para, grosso modo, a Europa a responsabilidade pelas decisões difíceis que têm de tomar ao nível interno9; seja porque as entidades europeias têm, de algum modo, sido negligentes e pouco próactivas na tarefa de envolver os cidadãos no projecto europeu ${ }^{10}$; seja, em última análise, porque as pessoas não estão particularmente motivadas ou mesmo de todo receptivas para assumirem um papel mais interventivo neste processo, a verdade é que parece

\footnotetext{
${ }^{9}$ Comissão Europeia, 2005: 3. Fenómeno que, seguindo Ana Lúcia Terra (2008: 254), encontra as suas raízes na década de 1980, altura em que eram já notórios os conflitos entre a agenda europeia e as nacionais.

${ }^{10}$ Veja-se a este respeito o estudo conduzido por Terra (2008), especialmente as pp. 292-293, 296-307, 365-369, 373-393. A autora promove um trabalho de âmbito histórico que abarca os sucessivos relatórios das instituições comunitárias a propósito do défice de comunicação da União Europeia, desde a década de 1980 , bem como às soluções que, no período sub judice, pouco ou nada mudaram. A novidade neste discurso, nos anos mais recentes, é, como adiante veremos, a ênsafe colocada nas ferramentas da sociedade da informação.
} 
existir um gradual afastamento entre os povos e as instituições europeias. Tal traduz-se não apenas na crescente dificuldade na aprovação e posterior ratificação dos Tratados, como de igual modo num progressivo enfraquecimento da mensagem europeia. Com efeito, diferentes estudos atribuem tal percepção a uma política de comunicação europeia que nem sempre se revela eficaz na prossecução dos seus objectivos. Tal situação, pensamos, ocorre a dois níveis. Desde logo, a União Europeia revelou-se incapaz de estabelecer canais de comunicação com os cidadãos, esclarecendo, informando, motivando e envolvendo. Noutro sentido, a política de comunicação praticada pelas instituições europeias não conseguiu estimular a emergência de uma esfera pública à escala continental.

A noção de esfera pública definida na década de 1960 por Habermas assume, hoje, no quadro da discussão acerca da integração europeia, um papel central. É no seguimento deste trabalho que vários investigadores vêm reflectindo acerca da emergência de uma esfera pública que transcenda as fronteiras nacionais, devido justamente ao facto de os assuntos públicos se terem também sobreposto às barreiras políticas (Os, et al., 2007: 757). No entanto, impõe-se perceber, mais em concreto, este fenómeno: será que assistimos ao nascimento de uma esfera pública à escala europeia, i.e., verdadeiramente supranacional ou, estamos, pelo contrário, perante um processo de europeização das esferas públicas nacionais (ou seja, ante uma situação em que o discurso europeu e os temas europeus têm vindo a invadir cada um dos espaços públicos dos Estados-Membros) ${ }^{11}$. Vários académicos pensam que estamos perante este segundo cenário, uma vez que não existem partidos políticos ou grupos de interesse supra-nacionais, não existem meios de comunicação europeus, não existe uma identidade europeia e, por último, é bem conhecida a manta de retalhos linguística da Europa. De resto, como escreve Risse (2003, apud Os et al., 2007: 758) "[...] uma esfera pública europeia não cai do céu e não pré-existe fora do discurso social e político. Ao invés, está a ser construída através de práticas sociais e discursivas criando um horizonte de referência comum e, ao mesmo tempo, uma comunidade transnacional de comunicação acerca de assuntos que nos preocupam 'como europeus' em vez de como ingleses, franceses, alemães ou neerlandeses".

\footnotetext{
${ }^{11}$ Um amplo conjunto de autores (entre os quais Eder e Kanter, 2000 e Gerhards, 2000, referidos em Os, et al., 2007: 758) referem que, para se poder falar de uma europeização da esfera pública, é necessário avaliar o discurso a partir de uma perspectiva que vá para lá do mero interesse nacional de cada actor. Outros acrescentam ainda que, além de comunicar temas europeus, é necessário que estes intervenientes comuniquem também a partir de uma perspectiva europeia.
} 
Para que possa falar-se numa efectiva esfera pública europeia, Peters entende, por seu lado, necessária a verificação cumulativa de três condições: 1) a existência de, grosso modo, trocas culturais entre os diferentes Estados-Membros; 2) que esses fluxos sejam mais intensos no interior do espaço comunitário quando em comparação com o exterior dessas fronteiras, e; 3) que a comunidade imaginada de que nos fala Anderson transcenda as fronteiras nacionais e se fixe no espaço geográfico correspondente ao da União. No entanto, e segundo a sua perspectiva, as esferas públicas nacionais têm-se revelado espantosamente resilientes contra as tentativas de criação de um espaço Europeu, pelo que as investigações levadas a cabo na Universidade de Bremen apontam para que, no melhor dos cenários, a velocidade de concretização de um tal espaço público europeu seja muito reduzida. De facto, "[...] um "nós" comum europeu como um fundo permanente ou ponto de referência dos debates públicos na realidade não existe" (Peters, 2004: 4, tradução nossa, aspas no original). Isto não implica, porém, que em certas áreas segmentadas não se possa falar já de um discurso europeizado. Peters aponta o caso da imprensa financeira que se tornou particularmente transnacional, tal como, de igual modo, o debate cultural entre as elites e os media intelectuais.

\section{Nova Política de Comunicação da União Europeia}

O "não" de franceses e neerlandeses ao Tratado Constitucional Europeu de 2005 representou o falhanço de mais de uma década de política de comunicação, das políticas e do projecto europeu (Europe 2020, 2005: 1). Como sabemos, na sequência deste revés, no final do Conselho Europeu de Junho de 2005, "os Chefes de Estado e de Governo adoptaram uma declaração sobre a "ratificação do Tratado que estabelece uma Constituição para a Europa". Esta declaração apelava a um "período de reflexão", na sequência do "não" da França e dos Países Baixos à Constituição Europeia" (Comissão Europeia, 2005 a : 1, aspas no original).

Sucederam-se então as declarações de intenção no sentido de envolver mais os povos, de comunicar melhor os temas europeus, de ouvir os eleitores e respectivas preocupações, de implementar acções concretas para diminuir a distância e o desconhecimento dos cidadãos sobre a Europa, bem como, promover a sua efectiva participação no objectivo da União. Entre a prolixa actividade da Comissão neste domínio destacam-se, no período em questão, três documentos estratégicos: o Action Plan to Improve Communicating Europe by the Commission, o Plano D para a 
Democracia, o Diálogo e o Debate e o Livro Branco sobre uma Política de

\section{Comunicação para a Europa.}

Tendo em vista a mitigação do défice de comunicação, do qual decorre, também, uma certa percepção de défice democrático, estes documentos pretendiam inaugurar uma nova era no relacionamento entre as instituições europeias e os seus diferentes públicos, fundada no diálogo e no debate com todos os interlocutores.

Esta nova abordagem centrava-se em torno de três ideias fundamentais: 1) escutar - a comunicação é um diálogo, não uma via de sentido único. As instituições da UE não se devem ocupar apenas em informar os cidadãos, antes aceitar que estes pretendem fazer ouvir a sua voz e participar directa e activamente no projecto de construção europeia; 2) comunicar - as actividades e políticas da UE, bem como o seu impacto na vida quotidiana das pessoas deve ser comunicado de uma forma perceptível e deve existir um seguimento dessas iniciativas, e; 3) ligar aos cidadãos a partir de efectiva presença/deslocação ao local (going local) - é imprescindível que a Comissão compreenda as audiências regionais e nacionais no sentido de melhor fazer passar a sua mensagem (Comissão Europeia, 2005 $\left.{ }^{\mathrm{b}}: 4\right)^{12}$.

Uma das áreas que merece especial referência nesta renovada política de comunicação da União Europeia é a Internet. A Internet constitui, como é frequentemente referido, um espaço que está acessível a um amplo conjunto de actores políticos - cidadãos, governos, partidos políticos, grupos de pressão, organizações sociais, entre outros - no sentido da partilha de informação, discussão dos mais variados temas e envolvimento na acção política (Os et al., 2007: 760). O especial enfoque na comunicação em linha por parte das diferentes instituições da União Europeia adquire

\footnotetext{
${ }^{12}$ Estes três pilares fundamentais serão concretizados, numa primeira fase, por meio de um conjunto de acções que a Comissão define como prioritárias: a) definição das prioridades comunicativas; b) coordenação activa das actividades no interior da Comissão através de uma rede composta pelas unidades de comunicação das diferentes Direcções Gerais; c) melhorar a capacidade da Comissão comunicar com os Estados-Membros como parte no sentido de chegar aos cidadãos; d) melhor uso das ferramentas de comunicação, através da disponibilização de conteúdos nas várias línguas da UE; e) descrição dos benefícios tangíveis das políticas da Comissão através de resumos das suas propostas, e; f) desenvolver uma comunicação mais profissional através do recrutamento e formação de especialistas na área (Comissão Europeia, 2005b: 5). Outras iniciativas igualmente incluídas no documento dizem respeito ao aumento do diálogo e transparência com vista a uma maior participação; maior preocupação no sentido de se alcançar uma linguagem simples e clara (livre do jargão e da gíria europeus); investimento nos canais de retorno da comunicação através da rede das Representações, centros de contacto e informação; adopção de uma postura de escutar e comunicar com as pessoas localmente através das Representações nacionais da Comissão nos diferentes Estados-Membros (identificando as audiências-alvo, procurando compreender as idiossincrasias de cada país, usar os media nacionais e regionais para fazer ouvir a voz da Comissão, organizar eventos de comunicação nacionais e promovendo audiências e visitas dos jornalistas às instituições europeias); apoio ao desenvolvimento e implementação de redes e projectos comunicativos de matriz pan-europeia, entre outras (Comissão Europeia, 2005b: 5-13).
} 
especial relevância num quadro em que se verificam dificuldades acrescidas no sentido do cumprimento dos objectivos desta nova abordagem à política de comunicação.

Num tal contexto, em que, por um lado, os principais órgãos informativos capazes de dar voz à União Europeia estão a retirar os seus correspondentes de Bruxelas, limitando deste modo a difusão da mensagem europeia e, por outro, as ferramentas sucedâneas, como é o caso, principalmente, da Internet, não representam uma alternativa viável (por força das razões acima apresentadas), assistiremos com grande probabilidade ao crescimento do défice de comunicação e, concomitantemente, da percepção correspondente a uma menor democraticidade das instituições, levando também ao aumento de um certo sentimento de défice democrático.

Porém, esta aposta das instituições comunitárias nas ferramentas da sociedade da informação, enquanto instrumento privilegiado de divulgação da sua mensagem e de um contacto mais directo com os cidadãos, apenas poderá oferecer um retorno positivo se, na mesma medida, forem promovidas as medidas necessárias tendentes à mitigação ou superação das profundas desigualdades registadas neste domínio.

Na linha de Os et al. (2007: 760) a primeira geração de ciber-optimistas (também referidos como tecno-deterministas) salientou as oportunidades que a Internet oferece no sentido de aumentar os processos de deliberação e decisão directa, no sentido de um melhoramento da democracia (são os casos de Rheingold, Gates, Negroponte, Dertouzos, Mitchell, etc.). Estas teses vieram a ser posteriormente contraditadas pelos ciber-pessimistas (Webster, May, Garnham, entre outros), os quais afirmavam que as múltiplas divisões digitais, ao invés de aproximarem os cidadãos e de aumentarem a participação criavam, na verdade, novas desigualdades. Por seu turno, as propostas de Norris e autores da mesma linha (Shenk, Castells, Cardoso, Hargittai, e outros) reconhecem o potencial transformador da Internet no âmbito do processo democrático, ainda que, haja a necessidade de, primeiramente, indivíduos e sociedades superem os desafios colocados pelas TIC.

Interessa-nos, por conseguinte, perceber de que modo poderá uma estratégia de comunicação desenvolvida a partir, maioritariamente, dos canais em linha, e suportada por uma promoção da sociedade da informação a partir de uma perspectiva técnica e económica, contribuir para a diminuição do défice de comunicação da União Europeia? 


\section{Análise Documental - metodologia}

A metodologia escolhida para a realização da análise documental dos enquadramentos que a seguir se desenvolve tem por base um modelo próprio que parte do cruzamento de várias técnicas de análise anteriormente usadas nos trabalhos de DiMaggio et al. (2001 e 2004), Hargittai (2010 e 2007), Bustelo et al. (2004 e 2006), Stewart et al. (2006), Dombos, et al. (2012), Epstein et al. (2011) Peters e Wester (2006), Rein e Schön (1993).

A análise parte do exame dos documentos produzidos pela Comissão Europeia, a partir do ano de 2000, tendo por objecto as temáticas da sociedade da informação e política de comunicação. Em concreto, incide sobre: Plano D para a Democracia, o Diálogo e o Debate (Comissão Europeia, 2005 ); Action Plan to Improve Communicating Europe by the Commission (Comissão Europeia, 2005 ${ }^{\mathrm{b}}$ ); Livro Branco sobre uma Política de Comunicação para a Europa (Comissão Europeia, 2006); eEurope 2002: Uma Sociedade da Informação para Todos (Conselho Europeu e Comissão Europeia, 2000); eEurope 2005: Uma Sociedade da Informação para Todos (Comissão Europeia, 2002); i2010 - Uma Sociedade da Informação Europeia para o Crescimento e para o Emprego (Comissão Europeia, 2005c); Livro Branco Modernização da Normalização das TIC na UE - O Caminho a Seguir (Comissão Europeia, 2009 $)$; Uma estratégia para a I\&D e a Inovação no domínio das TIC na Europa: subir a parada (Comissão Europeia, 2009º); Comunicação Sobre as Futuras Redes e a Internet (Comissão Europeia, 2008); Uma Agenda Digital para a Europa (Comissão Europeia, 2010 ); Europe 2020 Flagship Initiative Innovation Union (Comissão Europeia, 2010 ${ }^{\mathrm{b}}$ ).

A opção sobre estes documentos explica-se pelo facto de expressarem de modo mais abrangente, focalizado e estruturado as políticas da União Europeia em matéria de comunicação e sociedade da informação. Embora outros escritos pudessem ser igualmente convocados para este exercício, pensamos, na linha de Stewart et al. (2006: 737:738) que os acima indicados registos fornecem as linhas gerais a partir das quais iniciativas mais concretas e dirigidas são elaboradas. Também na linha de Entman (1993) optámos por circunscrever a nossa abordagem aos exemplos acima indicados a uma análise que compreende três dimensões: identificação do problema, causas do problema, possíveis soluções. 
No sentido de conferirmos maior rigor ao nosso trabalho e, tendo também presente, na pista de Peters e Wester (2006), as tendências mais recentes no domínio da investigação qualitativa, bem como a existência no mercado de variadas ferramentas especialmente concebidas para tarefas de investigação, optámos por recorrer, neste âmbito, à aplicação de análise de dados Nvivo, versão 9.2.

Para isso, escolhemos seguir uma estratégia idêntica à de Stewart et al. (2006). Esta nossa opção justifica-se pelo facto do trabalho destes autores ter incidido justamente sobre esta problemática ${ }^{13}$. Assim, empreendemos uma análise de texto, a qual começou por identificar os termos mais frequentes em cada um dos documentos. Pensamos ser importante o emprego desta metodologia de contagem de palavras em virtude da recorrência de certos termos/expressões-chave poder de algum modo explicitar determinados padrões semânticos, i.e., tornar visíveis algumas tendências/preferências discursivas presentes nos documentos analisados que nos ajudam a detectar possíveis opções. Por outro lado, na linha de Stewart et al., 2006: 3, esta estratégia revela-se igualmente útil na definição, a jusante, das próprias categorias de codificação. No tocante a este ponto específico, optámos, como de resto já acima referimos, por seguir uma estrutura de nós com os enquadramentos habituais de 'causas', 'consequências', 'soluções' (Entman,1993).

No entanto, a partir das várias leituras exploratórias que, em diferentes momentos, empreendemos aos documentos analisados concluímos ser útil a definição de três categorias principais para codificação dos dados recolhidos: 'políticas de comunicação', 'políticas de sociedade da informação', acções que cruzavam as duas primeiras categorias, i.e., acções que combinavam comunicação e sociedade da informação e vice-versa. Entendemos ser igualmente pertinente que, no campo das 'soluções', tanto as categorias de défice de comunicação como de sociedade da informação, fosse introduzido um maior grau de refinamento ${ }^{14}$. Por seu lado, a categoria

13 A diferença mais saliente é que, ao passo que a análise de Stewart et al. (2006) se centrou na confrontação entre os relatórios americanos e europeus referentes às políticas de promoção da sociedade da informação, a nossa visou apenas os últimos, procurando perceber/medir o impacto destas políticas na diminuição do défice de comunicação das instituições europeias.

14 Assim, no respeitante ao nó/enquadramento 'soluções', a categoria de sociedade da informação foi dividida em (1) ambiente, sustentabilidade e qualidade de vida; 2) economia e mercados; 3) investigação \& desenvolvimento e tecnologia; 4) política e legislação; 5) sócio-cultural). Na primeira sub-categoria foram codificadas todas as referências directamente relacionadas com ambiente, alterações climáticas, gestão racional da energia, sustentabilidade, transportes, lazer, saúde e apoio às populações idosas. Em economia e mercados codificámos todas as menções constantes dos documentos analisados a respeito de crescimento e desenvolvimento económico, investimento, emprego/trabalho e desemprego, mercados, desregulamentação e integração dos mercados, mercado comum. Todas as referências a tecnologia, 
défice de comunicação (políticas de comunicação / políticas de combate ao défice de comunicação), no que respeita ao nó/enquadramento 'soluções' foi também ela estruturada em torno de três sub-eixos ${ }^{15}$. Contrariamente à opção que seguimos para o nó/enquadramento 'soluções', entendemos não se justificar idêntico desdobramento nos nós 'causas' e 'consequências', dado que todos os documentos apresentam um pendor claramente orientado para soluções, mais do que para o estudo de causas ou consequências.

\section{Resultados}

Antes de procedermos a uma leitura qualitativa dos resultados, importa apresentar uma primeira leitura de base quantitativa a partir da qual se justifica a segunda análise. Assim, a primeira análise incidiu sobre as cem (100) palavras/expressões mais frequentes com tamanho igual ou superior a três (3) caracteres, a qual permite, por um lado, excluir artigos (o/a/os/as) e partículas de ligação (e, de, etc.), ao passo que inclui acrónimos (TIC e ICT, por exemplo).

Desta partimos para a elaboração de uma segunda tabela mais refinada, que reúne as 30 palavras mais frequentes (pesquisa contextual) contextualmente ligadas aos assuntos que nos encontramos a estudar: políticas de comunicação e políticas de promoção da sociedade da informação. Registe-se, por isso, a frequência de algumas palavras/ramos de palavras, as quais, uma vez agrupadas em escassas sete categorias ${ }^{16}$ nos permitem a detecção dos elementos-chave dos documentos trabalhados (Tabela 1).

investigação e desenvolvimento, inovação, patentes, e afins foram codificadas na terceira categoria. $\mathrm{Na}$ quarta, agrupámos as alusões respeitantes a iniciativas políticas, legislativas, programas, acções, etc., que tenham por origem agentes políticos e/ou legislativos. Por fim, na última categoria, seleccionamos os elementos referentes a sociedade, desenvolvimento social, inclusão social, educação e formação, combate ao fosso digital, cidadania, cultura e artes. Vd. Tabela 3 e Gráfico 3.

15 A saber: 1) cidadania e participação, 2) comunicação, 3) política e instituições. Na primeira, codificámos todas as referências que encontrámos a propósito de um maior envolvimento/participação dos cidadãos no processo político da União Europeia. Na segunda, encontram-se todas as menções a soluções para melhorar a política de comunicação e instrumentos de comunicação sobre a União Europeia (incluindo relação com os cidadãos, com os media, promoção de debates e sessões de esclarecimento, entre outros). Por último, as referências relacionadas com a comunicação institucional foram codificadas na sub-categoria política e instituições (onde se incluem planos de acção, programas de comunicação e afins). Vd. Tabela 3 e Gráfico 3.

${ }^{16}$ Salientemos também que, nestas sete categorias, se agrupam 28 de entre os 30 termos (as excepções são 'community' e 'utilização') mais frequentes relacionados com a nossa investigação. As famílias de palavras mais frequentes são, respectivamente: 1) europeu (europeias, Europa, europeu, europeus, europe), com 1345 ocorrências; 2) programa (políticas, acção, plano, programa, acções, iniciativa, action) repete-se 1100 vezes; 3) tecnologias (Internet, acesso, tecnologias, digital, segurança, utilização) 935 observações; 4) comissão (comissão, commission) devolve 649 resultados; 5) cidadãos (públicos, 
No tocante à análise das categorias interpretativas deve enfatizar-se primeiramente que, de um total de 11 documentos analisados, 8 versam sobre a problemática da sociedade da informação e, apenas 3 se reportam a aspectos relacionados com políticas de comunicação. Por outro lado, efectuámos um total de 1387 codificações. Estas distribuem-se entre os 11 textos que compõem as nossas fontes e 15 nós que correspondem ao universo total de categorias e sub-categorias. Foram codificadas, em média, 92 ocorrências por nó, ao passo que, por fonte, o valor médio de codificações cifrou-se em 126 (Tabela 3).

Verifica-se, também, que os documentos Agenda Digital (Comissão Europeia, 2010 ) e eEurope 2002 (Conselho Europeu e Comissão Europeia, 2000), se destacam dos demais pelo número de referências codificadas. Uma tal situação pode explicar-se por se encontrarem também entre os registos mais extensos. No extremo oposto, encontramos o Livro Branco TIC's (Comissão Europeia, 2009 $)$ e o Action Plan (Comissão Europeia, 2005 ), que contam 65 codificações cada. No caso do documento Action Plan um tão reduzido número de codificações não deixa de causar alguma surpresa, posto que, se trata do documento pelo qual a União Europeia (designadamente a Comissão) se propõe empreender uma reflexão (na ressaca dos insucessos na ratificação do Tratado Constitucional verificados em França e nos Países Baixos) aos défices democrático e de comunicação da União (Gráficos 1 e 2). Na verdade, estes gráficos revelam-nos ainda um segundo dado assaz interessante: os três registos directamente relacionados com políticas de comunicação (Action Plan (Comissão Europeia, 2005 ${ }^{\mathrm{b}}$ ), Livro Branco da Comunicação (Comissão Europeia, 2006) e Plano D (Comissão Europeia, 2005 )) contabilizam respectivamente, 65, 118 e 90 codificações. Em qualquer dos casos, bem distantes (especialmente no primeiro e terceiro casos) da média de codificações por registo que é, conforme já atrás reportámos, de 126.

Um outro dado particularmente relevante é a forte orientação da informação trabalhada para 'soluções' ao invés do estudo/apuramento de 'causas' e 'consequências' das dimensões de análise. Juntas estas últimas reúnem apenas 373 codificações, de um total de 1387. E, neste particular, destaque para as soluções em matéria de promoção da sociedade da informação, que recolhem mais do triplo das observações codificadas (um total de 301 para uma média de 96 - Tabela 3).

cidadãos, sociedade), 578 ocorrências; 6) comunicação (informação, comunicação, conteúdos), 537 referências e, finalmente; 7) estados (estados, nacionais) 407. 
Não causa, no entanto, qualquer estranheza a primazia de codificações relacionadas com a dimensão de análise sociedade da informação, em detrimento daquela que versam sobre as políticas de Comunicação. Esta maior preponderância explica-se pelo facto de, entre a nossa amostra, aproximadamente $3 / 4$ do total de registos analisados incidirem sobre esta problemática. Note-se, porém, a quase ausência de pontos de contacto entre as fontes e as categorias das ocorrências das duas dimensões analisadas (Tabela 3 e Gráfico 3). Ora, tais resultados deixam entender uma fraca interligação entre iniciativas, bem como, a ausência de políticas integradas de promoção da sociedade da informação e de combate ao défice de comunicação.

A concluir a explicitação dos resultados obtidos duas últimas indicações, cremos, as mais determinantes: 1) o excessivo peso, no campo das soluções, de três dimensões (política, economia e tecnologia) e, 2) a quase ausência de codificações compreendendo o cruzamento entre políticas de Comunicação e políticas de promoção da sociedade da informação. Analisando os resultados da codificação que empreendemos, fica claro que, neste capítulo, muito há ainda a fazer. Na verdade do já referido total de 1387 codificações efectuadas, apenas $25^{17}$ (i.e., $1,8 \%$ do total) encaixam nesta categoria, o que é, estamos em crer, preocupantemente escasso.

\section{Conclusões}

As conclusões que retiramos da análise que empreendemos aos documentos, a que já atrás aludimos, podem arrumar-se, partindo dos resultados obtidos e apresentados no tópico anterior, em cinco ideias principais: 1) a agregação das palavras mais frequentes resume-se em 7 categorias; 2) os documentos analisados incidem mais sobre 'soluções' do que sobre 'causas' ou 'consequências'; 3) regista-se uma prevalência dos temas de políticas de promoção sociedade da informação sobre aqueles que tratam da política de comunicação e, designadamente, de combate ao défice de comunicação, e nesses, prevalecem as perspectivas política, económica e técnica; 4) os documentos especificamente consagrados a esta última problemática (política de comunicação) apresentam um número de codificações inferior à média; 5) são quase inexistentes referências cruzadas entre as duas dimensões analisadas, i.e., entre promoção da sociedade da informação e redução do défice de comunicação.

\footnotetext{
${ }^{17}$ Causas: 1; Consequências: 0; Soluções: 24. Cf. Tabela 3.
} 
1. A pesquisa aos termos/palavras mais frequentes, uma vez depurada de modo a considerar apenas as ocorrências directamente relacionadas com as dimensões de análise em estudo, veio a apurar que estas podem arrumar-se em 7 categorias/conceitos: europa, programa, tecnologias, comissão, cidadãos, comunicação, estados. Estas 7 palavras guarda-chuva são afinal guardiãs da ideia central dos textos trabalhados, em resumo, algo que se traduziria numa frase do género: "a Comissão desenvolverá, em parceria com os Estados-Membros, os programas adequados no sentido de melhorar a comunicação sobre a Europa e estimular o uso das tecnologias pelos cidadãos

2. Vimos atrás que os registos analisados procuram muito mais lançar soluções, do que ater-se no estudo de causas e/ou consequências. Dir-se-ia que, estando o diagnóstico (de causas e consequências) feito, o que importa é apresentar projectos de solução. Cremos, contudo, que a primeira parte, i.e., o diagnóstico está longe de estar concluído. $\mathrm{Na}$ verdade, parece, e as declarações de vários intervenientes com responsabilidades na condução da política europeia vêm apontado nessa direcção, que os sucessivos planos/programas de acção têm fracassado, justamente, porque ainda não se investiu o tempo necessário com vista ao estudo rigoroso de causas e consequências que, via de regra, se circunscrevem a declarações tidas por definitivas, vagas e escassamente ancoradas na realidade.

3. Os documentos escolhidos para esta análise incidem principalmente sobre as temáticas da sociedade da informação (do total de 11, 8 versam este assunto, ao passo que apenas 3 estão relacionados com as políticas de comunicação). Saliente-se, no entanto, que pesem embora as muitas declarações de intenção atestando a importância de uma nova política de comunicação, verifica-se uma clara subalternização destes temas face aos demais ${ }^{19}$. Estamos em crer, aliás, que os três documentos que analisámos e que representam o núcleo duro da 'nova' política de comunicação da União Europeia, surgidos como resposta ao fracasso do Tratado Constitucional, não passam disso mesmo: uma reacção atrasada, pouco sincera e sem sequência.

Em sentido contrário, registamos o protagonismo recolhido pelas políticas de promoção da sociedade da informação que dispõe inclusive de um portal multilingual

\footnotetext{
${ }^{18}$ Ideias próximas desta encontramo-las, em quase todos os documentos trabalhados. Seja no Plano D, Livro Branco da Comunicação, eEurope 2002 ou 2005, i2010, com todos estes elementos ou apenas parte, esta é uma ideia omnipresente nos registos trabalhados.

${ }^{19}$ Num estudo de 2008, Ana Lúcia Terra, empreende um recenseamento aos sucessivos programas de comunicação da Europa e dos temas europeus. Aí, a autora deixa bem evidente que esta sempre foi uma preocupação menor dos decisores políticos que emergia no rescaldo de grandes crises (via de regra após processos de revisão dos Tratados), para logo voltar a desaparecer da agenda mediática.
} 
especificamente consagrado à temática ${ }^{20}$. Ora, mesmo tendo presente um maior protagonismo das demais dimensões (social, cultural, comunicacional, etc.) para lá da Santíssima Trindade (economia, tecnologia e política) nos documentos mais recentes, entendemos que a atenção que é dedicada a estas questões é ainda largamente lateral e o seu tratamento algo superficial, o que conduz, naturalmente a soluções que, é nossa convicção, pouco ou nada contribuem para resolver os problemas identificados.

4. Os documentos especificamente consagrados à política de comunicação) apresentam um número de codificações inferior à média. Já na apresentação dos resultados havíamos registado este ponto. E também então apontamos alguma estranheza quanto esta tendência. O menor número de textos não está de modo algum relacionado com este facto, dado que, o que está em causa é o número de codificações efectuadas por ensaio. Também parece pouco plausível que esta situação possa encontrar explicação num menor número de páginas destes documentos. Com efeito, o Plano D (26 páginas, 90 ocorrências) apresenta cerca de duas vezes e meia menos codificações do que o eEurope 2002 (28 páginas, 212 ocorrências). Com menor intensidade esta tendência acompanha (como aliás a Tabela 3 demonstra) os restantes textos. Não cremos ser possível, sem cair em exercícios de especulação, avançar uma explicação para este fenómeno. Pensamos no entanto poder existir uma relação entre este dado e um menor investimento das instituições comunitárias nas políticas de comunicação.

5. Verificámos que as referências cruzadas entre as duas dimensões analisadas, i.e., entre promoção da sociedade da informação e redução do défice de comunicação são quase inexistentes, contabilizando apenas um total de 25 ocorrências, sendo que destas 24 foram codificadas como 'soluções' e, nenhuma tem origem nos documentos relacionados com as políticas de promoção da sociedade da informação. Na realidade, o Plano D e o Livro Branco da Comunicação reúnem a totalidade das ocorrências codificadas nesta categoria. As intenções da Comissão, visando a promoção de uma 'nova' política de comunicação sobre os temas da Europa (escutando mais e indo ao encontro das preocupações dos cidadãos ${ }^{21}$ ), um maior envolvimento e participação dos cidadãos no projecto de construção europeia, recorrendo para tal às potencialidades das TIC, parece afinal não se ter concretizado nos documentos incidentes sobre o

\footnotetext{
${ }^{20}$ Em linha: http://europa.eu/pol/infso/index_pt.htm.

${ }^{21}$ Vd. Comissão Europeia (2005 ) e Comissão Europeia (2006).
} 
desenvolvimento da sociedade da informação, independentemente destes serem anteriores ou posteriores ao "período de reflexão".

Ora, uma tal situação como aquela que parece emergir das conclusões atrás avançadas, não poderá levar a outro desfecho que não ao incremento do sentimento de défice democrático nos cidadãos (fundado no défice de comunicação) e ao consequente aumento da indiferença, quando não mesmo oposição, ao projecto europeu. A esta soma-se ainda a presença, no discurso de muitos destacados dirigentes políticos, de sinais adicionais sugerindo que a Europa corre o risco de caminhar para uma dissolução (mais ou menos) ordeira se, entretanto, nada for feito no sentido de inverter as actuais tendências.

\section{Referências Bibliográficas}

ANDERSON, Peter J. e MCLEOD, Aileen (2004). "The Great Non-Communicator? The Mass Communication Deficit of the European Parliament and its Press Directorate". In JCMS 2004 Volume 42. Number 5. pp. 897-917. Oxford, UK e Malden, USA. Blackwell Publishing.

COMISSÃO EUROPEIA (2010a). Comunicação da Comissão ao Parlamento Europeu, ao Conselho, ao Comité Económico e Social Europeu e ao Comité das Regiões - Uma Agenda Digital para a Europa. Bruxelas. Documento de Trabalho. [em linha]: http://eur-lex.europa.eu/LexUriServ/LexUriServ.do?uri=COM:2010:0245:FIN:PT:PDF.

COMISSÃO EUROPEIA (2010b). Communication from the Commission to the European Parliament, the Council, the European Economic and Social Committee And the Committee of the Regions - Europe 2020 Flagship Initiative Innovation Union. Documento de Trabalho. [em linha]:

http://www.umic.pt/images/stories/publicacoes3/innovation-unioncommunication_en.pdf.

COMISSÃO EUROPEIA (2009a). Livro Branco - Modernização da Normalização das TIC na UE - O Caminho a Seguir. Bruxelas. Documento de trabalho. [em linha]: http://eur-lex.europa.eu/LexUriServ/LexUriServ.do?uri=COM:2009:0324:FIN:PT:PDF. 
COMISSÃO EUROPEIA (2009b). Comunicação da Comissão ao Parlamento Europeu, ao Conselho, ao Comité Económico e Social Europeu e ao Comité das Regiões - Uma estratégia para a I\&D e a Inovação no domínio das TIC na Europa: subir a parada. Documento de Trabalho. [em linha]: http://eurlex.europa.eu/LexUriServ/LexUriServ.do?uri=COM:2009:0116:FIN:PT:HTML.

COMISSÃO EUROPEIA (2009c). The 2009 Report on R\&D in ICT in the European Union. Documento de Trabalho. [em linha]: http://ftp.jrc.es/EURdoc/JRC49951.pdf.

COMISSÃO EUROPEIA (2008). Comunicação ao Parlamento Europeu, ao Conselho, ao Comité Económico e Social Europeu e ao Comité das Regiões - Comunicação Sobre as Futuras Redes e a Internet. Documento de trabalho. [em linha]: http://www.umic.pt/images/stories/com2008_0594pt01.pdf.

COMISSÃO EUROPEIA (2006). Livro Branco Sobre uma Politica de Comunicação Europeia. [em linha]:

http://europa.eu/documents/comm/white_papers/pdf/com2006_35_pt.pdf.

COMISSÃO EUROPEIA (2005a). Comunicação da Comissão ao Conselho, ao Parlamento Europeu, ao Comité Económico e Social Europeu e ao Comité das Regiões - Contributo da Comissão para o período de reflexão e para a fase posterior: Plano D para a Democracia, o Diálogo e o Debate. [em linha]: http://eurlex.europa.eu/LexUriServ/LexUriServ.do?uri=COM:2005:0494:FIN:PT:PDF.

COMISSÃO EUROPEIA (2005b). Communication to the Commission - Action Plan to Improve Communicating Europe by the Commission. [em linha]:

http://ec.europa.eu/dgs/communication/pdf/communication_com_en.pdf.

COMISSÃO EUROPEIA (2005c). Comunicação da Comissão ao Conselho, Parlamento Europeu, ao Comité Económico e Social Europeu e ao Comité das Regiões - i2010 - Uma Sociedade da Informação Europeia para o Crescimento e para o Emprego. Documento de trabalho. [em linha]:

http://www.umic.pt/images/stories/publicacoes/com_229_i2010_pt.pdf. 
COMISSÃO EUROPEIA (2002). Comunicação da Comissão ao Conselho, Parlamento Europeu, ao Comité Económico e Social e ao Comité das Regiões - eEurope 2005: Uma Sociedade da Informação para Todos. Documento de trabalho. [em linha]: http://eur-lex.europa.eu/LexUriServ/LexUriServ.do?uri=COM:2002:0263:FIN:PT:PDF.

CONRAD, Maximillian (2005). “'Listen, Communicate, Go Local' - Event Publics and the Construction of a European Public Sphere". Conferência proferida no CONNEX workshop on Democratic Accountability and Legitimacy In the EU. Uppsala, December $1-2,2005$.

CONSELHO EUROPEU (2010). Fertilização cruzada entre as iniciativas emblemáticas da estratégia Europa 2020 - "Uma Agenda Digital para a Europa" e "União da Inovação" - Conclusões do Conselho. [em linha]:

http://register.consilium.europa.eu/pdf/pt/10/st16/st16834.pt10.pdf.

CONSELHO EUROPEU (2003). Council Resolution on the Implementation of the eEurope 2005 Action Plan. Documento de Trabalho.

CONSELHO EUROPEU e COMISSÃO EUROPEIA (2000). eEurope 2002: Uma Sociedade da Informação para Todos. Plano de Acção Preparado pelo Conselho e pela Comissão Europeia para o Conselho Europeu da Feira. Documento de trabalho. [em linha]:

http://ec.europa.eu/information_society/eeurope/i2010/docs/2002/action_plan/actionpla n_pt.pdf.

CROMBEZ, Christophe, (2003). "The Democratic Deficit In the European Union Much Ado about Nothing?". European Union Politics. Volume 4 (1). pp. 101-120. London, Thousand Oaks CA, New Delhi. SAGE Publications.

DIMAGGIO, Paul, HARGITTAI, Eszter, CELESTE, Coral, SHAFER, Steven (2004). "From Unequal Access to Differentiated Use: A Literature Review and Agenda for Research on Digital Inequality”. In NECKERMAN, Kathryn (ed.) (2004). Social Inequality. New York. Russell Sage Foundation, pp. 355-400. [em linha]: http://webuse.org/p/c05. 
DOMBOS, Tamas, KRIZSAN, Andrea, VERLOO, Mieke, ZENTAI, Violetta (2012).

Critical Frame Analysis: A Comparative Methodology for the 'Quality In Gender+ Equality Policies' (QUING) project. Budapest. Center for Policy Studies. Central European University.

ENTMAN, Robert M. (1993). "Framing: Toward Clarification of a Fractured Paradigm”. Journal of Communication 43(4), Autumn. pp. 51-58.

EUROPE 2020 (2005). Towards a "D for Democratisation" strategy Citizen. [em linha]: http://www.europe2020.org/en/section_democrat/140605.htm.

FIGUEIREDO, Alexandre (2012b). “As Iniciativas Europeias em Matéria de Promoção da Sociedade da Informação". In APARÍCIO, Maria Irene e FIGUEIREDO, Alexandre (eds.) (2012). Artciencia.com, Revista de Arte, Ciência e Comunicação, Year VII, issue 16, May-November 2012. [em linha]:

http://www.artciencia.com/index.php/artciencia/article/view/62/238.

GORJÃO-HENRIQUES, Miguel (2008a). Manual de Direito Comunitário. Coimbra. Almedina.

HARGITTAI, Eszter (2004). "Internet access and use In context". In New Media \& Society - Vol. 6 (1), pp. 137-143. London, Thousand Oaks, CA e New Delhi. SAGE Publications. [em linha]: http://webuse.org/p/a12.

MORAVCSIK, Andrew (2002). "In Defence of the 'Democratic Deficit': Reassessing Legitimacy in the European Union". In JCMS, Volume 40, Number 4, pp. 603-624. University Association for Contemporary European Studies. [em linha]: http://eu.wiley.com/WileyCDA/WileyTitle/productCd-JCMS.html.

OS, Renée van, JANKOWSKI, Nicholas W. e VERGEER, Maurice (2007). "Political Communication About Europe on the Internet During the 2004 European Parliament Election Campaign in Nine EU Member States”. In European Societies, 9:5, pp. 755775. London. Routledge. [em linha]: http://dx.doi.org/10.1080/14616690701412871. PETERS, Bernhard (2004). "Ach Europa”. In Eurozine. [em linha]: 
http://www.eurozine.com/pdf/2004-06-21-peters-en.pdf.

RISSE, Thomas, (ed.) (2003), Identities In Europe and the Institutions of the European Union. Lanham MD. Rowman \& Littlefield.

STEWART, Concetta M., GIL-EGUI, Gisela, TIAN, Yan e PILEGGI, Mairi Innes (2006). "Framing the digital divide: a comparison of US and EU policy approaches". New Media Society 2006 8: 731. [em linha]: http://nms.sagepub.com/content/8/5/731.

TERRA, Ana Lúcia Silva (2008). As políticas de informação e de comunicação da União Europeia: uma leitura diacrónica e exploratória no âmbito da Ciência da Informação (Dissertação de Doutoramento submetida à Faculdade de Letras da Universidade de Coimbra). Coimbra. Faculdade de Letras da Universidade de Coimbra. [em linha]: http://hdl.handle.net/10316/11215. 


\section{ANEXOS}

\section{a) Tabelas}

Tabela 2 - total de referências e total de nós

Tabela 1 - Palavras mais frequentes por categorias por fonte

\begin{tabular}{|l|c|}
\hline \multicolumn{1}{|c|}{ Família de palavras } & $\begin{array}{c}\text { Total de } \\
\text { ocorrências }\end{array}$ \\
\hline $\begin{array}{l}\text { europeu (europeias, Europa, europeu, europeus, } \\
\text { europe) }\end{array}$ & 1345 \\
\hline cidadãos (públicos, cidadãos) & 422 \\
\hline comunicação (informação, comunicação, conteúdos) & 537 \\
\hline $\begin{array}{l}\text { programa (políticas, acção, plano, programa, acções, } \\
\text { iniciativa, action) }\end{array}$ & 1100 \\
\hline comissão (comissão, commission) & 649 \\
\hline estados (estados, nacionais) & 407 \\
\hline $\begin{array}{l}\text { tecnologias (internet, acesso, tecnologias, digital, } \\
\text { segurança, utilização) }\end{array}$ & 935 \\
\hline
\end{tabular}

\begin{tabular}{|c|c|c|}
\hline Nome & Nós & Referências \\
\hline redes_futuras_internet & 7 & 82 \\
\hline Plano D & 6 & 90 \\
\hline Livro_branco_TIC & 6 & 65 \\
\hline Livro Branco & 7 & 118 \\
\hline i2010 & 7 & 138 \\
\hline I\&D_TIC & 7 & 96 \\
\hline europe 2020 & 7 & 133 \\
\hline eeurope2005 & 6 & 135 \\
\hline eeurope2002 & 7 & 212 \\
\hline agenda_digital & 7 & 253 \\
\hline Action Plan & 5 & 65 \\
\hline
\end{tabular}

Tabela 3 - Registo de elementos codificados por enquadramentos, categorias, fontes e médias

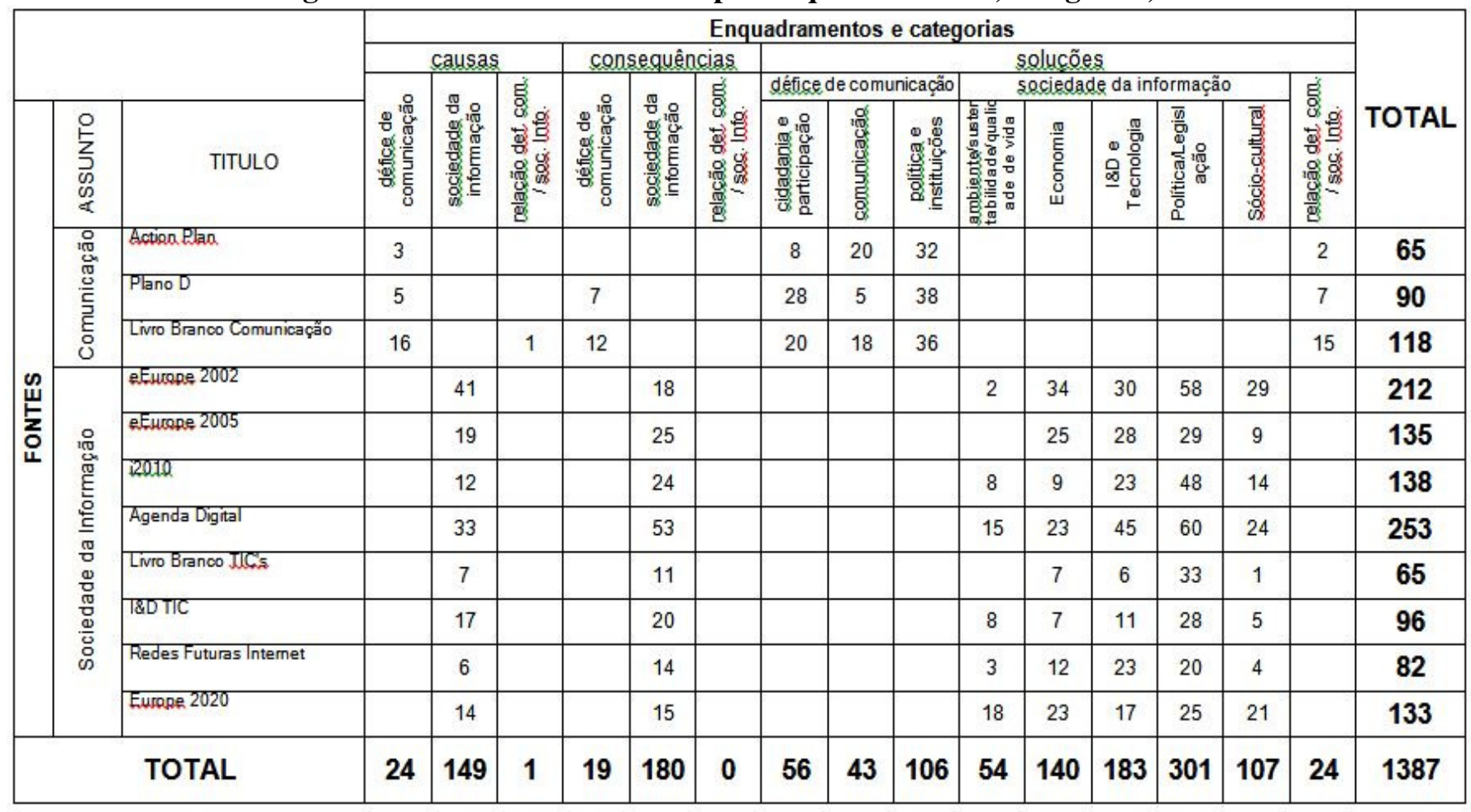




\section{b) Gráficos}

Gráfico 1 - Registo de elementos codificados por fonte



Gráfico 2 - número de referências codificadas por fonte (referências) e número de nós por fonte (nós)

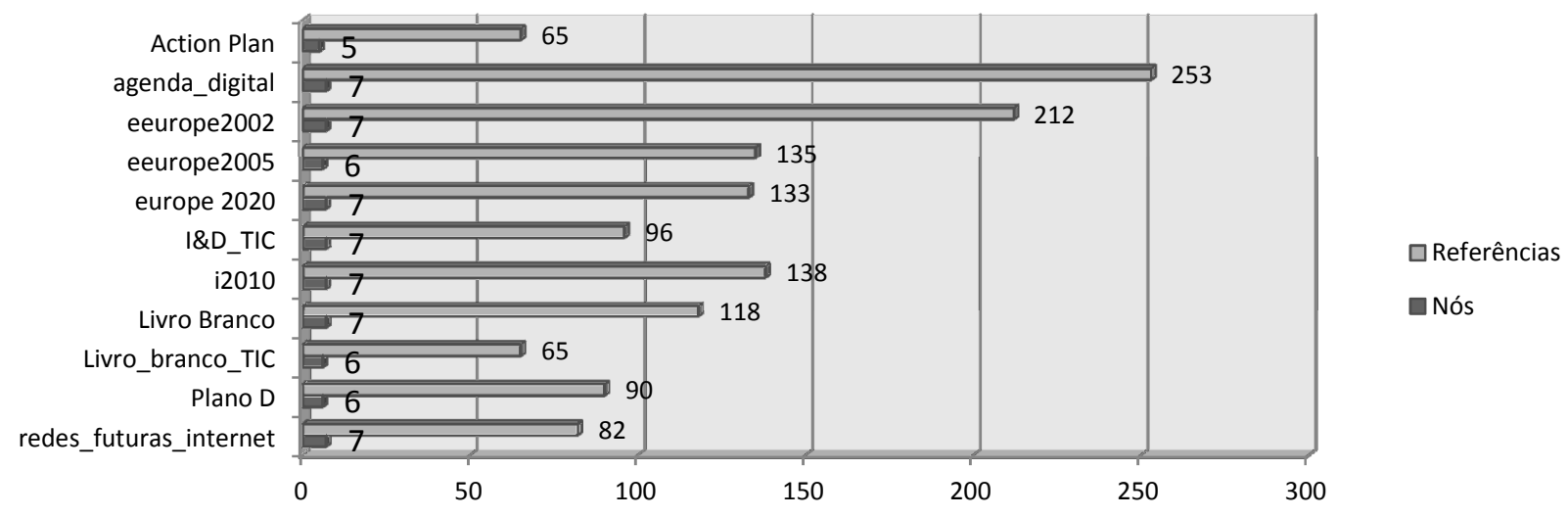

Gráfico 3 - Registo de elementos codificados por nó/categoria

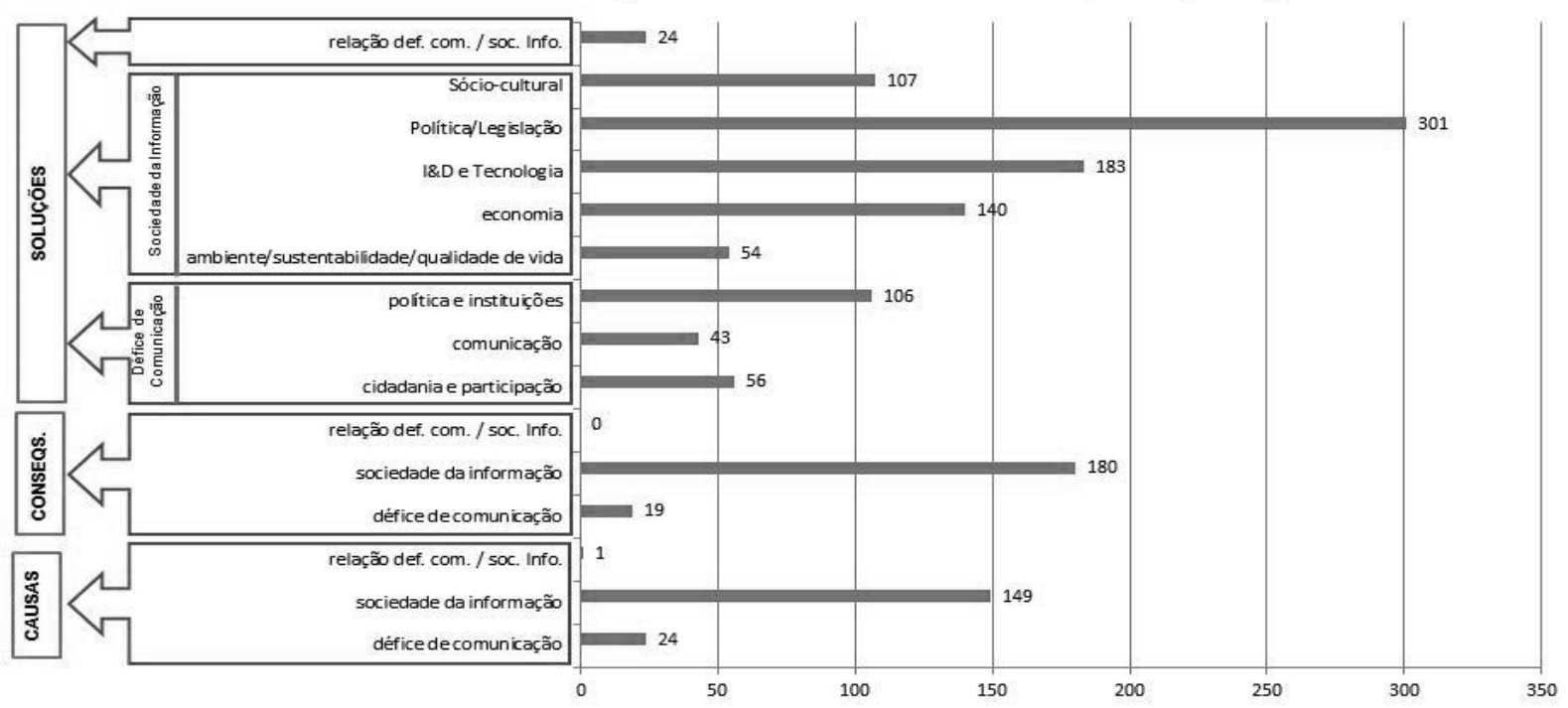

